\title{
Predictive value of microalbuminuria in patients with insulin-dependent diabetes of long duration
}

\author{
Carol M Forsblom, Per-Henrik Groop, Agneta Ekstrand, Leif C Groop
}

Fourth Department of

Medicine, Helsinki

University Hospital,

Unioninkatu 38, SF-00170

Helsinki, Finland

Carol M Forsblom, research

assistant

Per-Henrik Groop, research fellow

Agneta Ekstrand, resident

Leif C Groop, associate

professor

Correspondence to:

Dr Leif C Groop.

BM7 1992;305:1051-3

\section{Abstract}

Objective-To investigate the predictive value of microalbuminuria (albumin excretion rate $30-300$ $\mathrm{mg} / 24 \mathrm{~h}$ ) as a risk factor for overt diabetic nephropathy in patients with longstanding insulin dependent diabetes.

Design-10 year follow up of patients with normoalbuminuria (albumin excretion rate $<30 \mathrm{mg} / 24 \mathrm{~h}$ ), microalbuminuria (30-300 $\mathrm{mg} / 24 \mathrm{~h}$ ), and macroalbuminuria $(>300 \mathrm{mg} / 24 \mathrm{~h}$ ) based on two out of three timed overnight urine samples.

Setting-Outpatient clinic of Helsinki University Hospital.

Subjects -72 consecutive patients who had had insulin dependent diabetes for over 15 years.

Main outcome measures-Urinary albumin excretion rate, mortality, and prevalence of diabetic complications after 10 years.

Results-56 patients were re-examined at 10 year follow up, 10 had died, five were lost to follow up, and one was excluded because of non-diabetic kidney disease. At initial screening 22 patients had macroalbuminuria, 18 had microalbuminuria, and 26 had normal albumin excretion. Only five $(28 \%, 95 \%$ confidence interval $10 \%$ to $54 \%$ ) of the microalbuminuric patients developed macroalbuminuria during the $\mathbf{1 0}$ year follow up and none developed end stage renal failure. Two $(8 \%, 1 \%$ to $25 \%)$ normoalbuminuric patients developed macroalbuminuria and four $(15 \%, 4 \%$ to $35 \%)$ became microalbuminuric. Seven $(32 \%, 14 \%$ to $55 \%)$ of the macroalbuminuric patients developed end stage renal failure and $\operatorname{six}(27 \%, 11 \%$ to $50 \%)$ died of cardiovascular complications.

Conclusion-Microalbuminuria is not a good predictor of progression to overt nephropathy in patients with longstanding insulin dependent diabetes.

\section{Introduction}

About $40 \%$ of patients with insulin dependent diabetes will develop overt nephropathy, defined as an urinary albumin concentration above $300 \mathrm{mg} / \mathrm{l}^{12}$ Pro-

TABLE I-Characteristics of patients with insulin dependent diabetes at initial investigation. Values are mean (SE; range) unless stated otherwise

\begin{tabular}{lccc}
\hline & $\begin{array}{c}\text { Normoalbuminuria } \\
(<30 \mathrm{mg} / 24 \mathrm{~h})\end{array}$ & $\begin{array}{c}\text { Microalbuminuria } \\
(30-300 \mathrm{mg} / 24 \mathrm{~h})\end{array}$ & $\begin{array}{c}\text { Macroalbuminuria } \\
(>300 \mathrm{mg} / 24 \mathrm{~h})\end{array}$ \\
\hline No of patients (F/M) & $29(18 / 11)$ & $20(11 / 9)$ & $22(14 / 8)$ \\
Albumin excretion rate (mg/24 h) & $13(2 ; 3-28)$ & $92(15 ; 30-265)$ & $2327(364 ; 328-7800)$ \\
Age (years) & $35(2 ; 19-52)$ & $37(2 ; 27-50)$ & $33(1 ; 22-48)$ \\
Body mass index (kg/m) & $22 \cdot 7(0 \cdot 5 ; 18 \cdot 0-28 \cdot 3)$ & $23 \cdot 2(0 \cdot 6 ; 19 \cdot 2-28 \cdot 5)$ & $24 \cdot 1(1 \cdot 0 ; 18 \cdot 3-39 \cdot 9)$ \\
Age at onset of diabetes (years) & $13(1 ; 2-33)$ & $11(1 ; 1-24)$ & $12(1 ; 4-26)$ \\
Mean duration of diabetes (years) & $22(1 ; 15-38)$ & $26(1 ; 16-36)$ & $21(1 ; 15-28)$ \\
Glycated haemoglobin (\%) & $9 \cdot 9(0 \cdot 3 ; 5 \cdot 8-13 \cdot 3)$ & $10 \cdot 4(0 \cdot 3 ; 7 \cdot 6-13 \cdot 1)$ & $11 \cdot 2(0 \cdot 5 ; 7 \cdot 3-16 \cdot 6)$ \\
Insulin dose (IU/kg) & $0 \cdot 64(0 \cdot 03 ; 0 \cdot 36-1 \cdot 03)$ & $0 \cdot 74(0 \cdot 05 ; 0 \cdot 45-1 \cdot 24)$ & $0 \cdot 73(0 \cdot 04 ; 0 \cdot 38-1 \cdot 13)$ \\
No $(\%)$ with proliferative retinopathy & $6(21)$ & $10(50)$ & $22(100)$ \\
No(\%) with hypertension & & $6(30)$ & $16(73)$ \\
\hline & & & \\
\hline
\end{tabular}

gression to end stage renal failure occurs shortly after, indicating that macroalbuminuria (albumin excretion rate $>300 \mathrm{mg} / 24 \mathrm{~h}$ reflects an advanced stage of diabetic kidney disease. The finding that microalbuminuria (albumin excretion rate $30-300 \mathrm{mg} / 24 \mathrm{~h}$ ) indicates early diabetic nephropathy and predicts progression to overt nephropathy has allowed early diagnosis and preventive interventions at an early stage. $^{34}$ But most studies of microalbuminuria in diabetic nephropathy have included patients with a mean duration of diabetes of 12 to 14 years. ${ }^{3+}$ It is not known whether microalbuminuria has the same predictive value in patients with longstanding (more than 15 years) insulin dependent diabetes. This information is urgently needed in order to define appropriate screening and follow up programmes for diabetic patients.

\section{Patients and methods}

In 1980 we recruited from our outpatient clinic 72 consecutive patients with longstanding (over 15 years), insulin dependent diabetes who were negative for $\mathrm{C}$ peptide. All had urinary albumin excretion rates measured (table I). Patients were considered negative for $\mathrm{C}$ peptide if peptide concentration six minutes after an intravenous injection of $1 \mathrm{mg}$ glucagon was less than $0.2 \mathrm{nmol} / \mathrm{l}$. One patient was later excluded from the follow up study because of coexisting renal disease (proteinuria and haematuria were present at onset of diabetes). Ten patients died during the 10 year follow up period. The remaining patients were invited to participate in a second study in 1990. Five patients had moved from the region and were lost to follow up. The study protocol was approved by the ethics committee of the Fourth Department of Medicine, Helsinki University Hospital.

Information on patient survival and causes of death was obtained from medical records. Metabolic control had been followed by measuring concentrations of glycated haemoglobin, serum total cholesterol, high density lipoprotein cholesterol, and triglyceride. Urinary albumin excretion was measured in one 24 hour and two timed overnight urine samples, at the beginning and end of the follow up period. Normoalbuminuria was classified as an albumin excretion rate below $20 \mu \mathrm{g} / \mathrm{min}(<30 \mathrm{mg} / 24 \mathrm{~h})$, microalbuminuria as a rate of $20-200 \mu \mathrm{g} / \mathrm{min}(30-300 \mathrm{mg} / 24 \mathrm{~h})$, and macroalbuminuria as a rate over $200 \mu \mathrm{g} / \mathrm{min}(>300 \mathrm{mg} / 24 \mathrm{~h}$ ) in two out of three consecutive timed overnight urine samples (table I). However, in the tables and text albumin excretion rate is presented as $\mathrm{mg} / 24 \mathrm{~h}$. Blood pressure was measured in the supine position after 10 minutes' rest with a mercury sphygmomanometer. Patients were defined as having hypertension if their systolic blood pressure was $>160 \mathrm{~mm} \mathrm{Hg}$, their diastolic pressure was $>95 \mathrm{~mm} \mathrm{Hg}$, or they were taking antihypertensive drugs. 
Plasma glucose concentration was measured with a hexokinase method (Boehringer Mannheim, Mannheim, Germany) and glycated haemoglobin by microcolumn chromatography (Isolab, Akron, Ohio, United States). The reference level for the haemoglobin assay was $5-7 \%$. Plasma triglyceride and serum cholesterol concentrations were measured by commercially available methods (Boehringer Mannheim, Mannheim, Germany) and high density lipoprotein cholesterol after ultracentrifugation of plasma. Urine concentrations of albumin were determined immunoturbidimetrically. The sensitivity of the albumin assay was $5 \mathrm{mg} / \mathrm{l}$ and the coefficient of variation $7.5 \%$.

All results are expressed as the mean (SE) with 95\% confidence intervals. The Mann-Whitney test was used to test the equality of group means and $\chi^{2}$ test to test the significance of frequency differences.

\section{Results}

Twenty nine of the patients examined in 1980 were normoalbuminuric and 26 were available for re-examination in 1990 (figure). By 1990 two patients (8\%; 95\% confidence interval $1 \%$ to $25 \%$ ) had developed macro-

TABLE II-Initial characteristics of normoalbuminuric patients who did and did not progress to microalbuminuria or macroalbuminuria. Values are mean (SE; 95\% confidence interval) unless stated otherwise

\begin{tabular}{|c|c|c|c|}
\hline & Progression & No progression & $\mathrm{p}$ Value \\
\hline No of patients (F/M) & $6(4 / 2)$ & $20(11 / 9)$ & \\
\hline Albumin excretion rate $(\mathrm{mg} / 24 \mathrm{~h})$ & $16(4 ; 7$ to 25$)$ & $12(2 ; 8$ to 16$)$ & \\
\hline Age (years) & $28(3 ; 20$ to 36$)$ & $38(2 ; 34$ to 42$)$ & $<0.02$ \\
\hline Body mass index $\left(\mathrm{kg} / \mathrm{m}^{2}\right)$ & $23 \cdot 1(0 \cdot 9 ; 20 \cdot 8$ to $25 \cdot 4)$ & $22.7(0 \cdot 6 ; 21 \cdot 4$ to $24 \cdot 0)$ & \\
\hline Age at onset of diabetes (years) & $11(3 ; 4$ to 18$)$ & $15(2 ; 11$ to 19$)$ & \\
\hline Duration of diabetes (years) & $18(1 ; 15$ to 21$)$ & $23(1 ; 20$ to 26$)$ & $<0.02$ \\
\hline Insulin dose (IU/kg) & $0.81(0.06 ; 0.65$ to 0.97$)$ & $0.59(0.04 ; 0.51$ to 0.67$)$ & $<0.01$ \\
\hline Glycated haemoglobin (\%) & $10 \cdot 2(0 \cdot 6 ; 8 \cdot 5$ to $11 \cdot 9)$ & $9 \cdot 7(0 \cdot 4 ; 8.8$ to $10 \cdot 6)$ & \\
\hline Mean glycated haemoglobin $(\%)^{\star}$ & $11 \cdot 1(0.5 ; 9.9$ to 12.3$)$ & $9 \cdot 3(0.4 ; 8.5$ to $9 \cdot 9)$ & $<0.02$ \\
\hline Cholesterol $(\mathrm{mmol} / \mathrm{l})$ & $6 \cdot 2(0 \cdot 8 ; 4 \cdot 3$ to $8 \cdot 1)$ & $5 \cdot 6(0 \cdot 2 ; 5 \cdot 1$ to $6 \cdot 1)$ & \\
\hline High density lipoprotein cholesterol $(\mathrm{mmol} / \mathrm{l})$ & $1.4(0.1 ; 1.3$ to 1.5$)$ & $1.7(0.1 ; 1.5$ to 1.9$)$ & $<0.05$ \\
\hline Triglyceride $(\mathrm{mmol} / \mathrm{l})$ & $1.4(0.3 ; 0.7$ to $2 \cdot 1)$ & $1.0(0.1 ; 0.8$ to 1.2$)$ & \\
\hline Creatinine clearance $(\mathrm{ml} / \mathrm{s} 1.73 \mathrm{~m})$ & $1.52(0 \cdot 28 ; 0 \cdot 81$ to $2 \cdot 23)$ & $1.77(0.07 ; 1.61$ to 1.93$)$ & \\
\hline $\begin{array}{l}\text { No }(\% ; 95 \% \text { confidence interval) with } \\
\text { retinopathy }\end{array}$ & $2(33 ; 4 \%$ to $78 \%)$ & $2(10 ; 1 \%$ to $32 \%)$ & \\
\hline
\end{tabular}

* Mean value of all measurements during the follow up period.

TABLE III-Initial characteristics of microalbuminuric patients who did and did not progress to macroalbuminuria. Values are mean (SE; 95\% confidence interval) unless stated otherwise

\begin{tabular}{|c|c|c|}
\hline & Progression & No progression \\
\hline No of patients $(\mathrm{F} / \mathrm{M})$ & $5(3 / 2)$ & $13(7 / 6)$ \\
\hline Albumin excretion rate $(\mathrm{mg} / 24 \mathrm{~h})$ & $144(39 ; 36$ to 252$)$ & $79(16 ; 45$ to 113$)$ \\
\hline Age (years) & $42(3 ; 35$ to 50$)$ & $35(2 ; 31$ to 39$)$ \\
\hline Body mass index $\left(\mathrm{kg} / \mathrm{m}^{2}\right)$ & $25.8(0.9 ; 23.3 \text { to } 28.3)^{\star}$ & $22 \cdot 3(0 \cdot 7 ; 20 \cdot 8$ to $23 \cdot 8)$ \\
\hline Age at onset of diabetes (years) & $16(2 ; 10$ to 22$)$ & $10(2 ; 6$ to 14$)$ \\
\hline Duration of diabetes (years) & $26(1 ; 22$ to 30$)$ & $25(2 ; 21$ to 29$)$ \\
\hline Insulin dose (IU $/ \mathrm{kg})$ & $0.66(0.10 ; 0.39$ to 0.93$)$ & $0.78(0.07 ; 0.63$ to 0.93$)$ \\
\hline Glycated haemoglobin $(\%)$ & $11.1(0.7 ; 9.3$ to 12.9$)$ & $10 \cdot 1(0 \cdot 5 ; 9 \cdot 2$ to $11 \cdot 1)$ \\
\hline Mean glycated haemoglobin $(\%) \dagger$ & $10 \cdot 5(0 \cdot 8 ; 8 \cdot 8$ to $12 \cdot 2)$ & $9 \cdot 5(0 \cdot 3 ; 8 \cdot 8$ to $10 \cdot 1)$ \\
\hline Cholesterol $(\mathrm{mmol} / \mathrm{)})$ & $6.6(0.6 ; 5.0$ to 8.2$)$ & $6.0(0.3 ; 5.3$ to 6.7$)$ \\
\hline High density lipoprotein cholesterol $(\mathrm{mmol} / \mathrm{l})$ & $1 \cdot 4(0 \cdot 2 ; 0 \cdot 8$ to $2 \cdot 0)$ & $1.7(0 \cdot 2 ; 1 \cdot 4$ to $2 \cdot 0)$ \\
\hline Triglyceride $(\mathrm{mmol} / \mathrm{l})$ & $1.1(0 \cdot 1 ; 0.7$ to 1.5$)$ & $1 \cdot 1(0.2 ; 0.7$ to 1.5$)$ \\
\hline Creatinine clearance $(\mathrm{ml} / \mathrm{s} 1.73 \mathrm{~m})$ & $1.56(0.19 ; 1.03$ to 2.09$)$ & $2.00(0.20 ; 1.88$ to $2 \cdot 12)$ \\
\hline $\begin{array}{l}\text { No }(\% ; 95 \% \text { confidence interval) with } \\
\text { retinopathy }\end{array}$ & $3(60 ; 15 \%$ to $95 \%)$ & $3(23 ; 5 \%$ to $54 \%)$ \\
\hline $\begin{array}{l}\text { No }(\% ; 95 \% \text { confidence interval) with } \\
\text { hypertension }\end{array}$ & $3(60 ; 15 \%$ to $95 \%)$ & $3(23 ; 5 \%$ to $54 \%)$ \\
\hline
\end{tabular}

${ }^{\star} \mathrm{p}<0.02$ for difference between groups. albuminuria and four $(15 \% ; 4 \%$ to $35 \%)$ had progressed to microalbuminuria, 20 patients still remained normoalbuminuric. Two patients died: one who remained normoalbuminuric died of malignancy and one who became microalbuminuric died of myocardial infarction. None of the normoalbuminuric patients had hypertension at the start of the study. Normoalbuminuric patients who progressed to micro- $\frac{}{3}$ albuminuria or macroalbuminuria had higher glycated $c$ haemoglobin concentrations during the follow up $\vec{F}$ period $(\mathrm{p}<0.02)$, lower high density lipoprotein $\stackrel{\text { ? }}{+}$ cholesterol concentration $(p<0 \cdot 05)$, required a higher insulin dose $(\mathrm{p}<0 \cdot 01)$, and had a shorter duration of $\frac{\overline{\bar{O}}}{\overline{0}}$ diabetes $(p<0.02)$ than patients who remained normo- $\frac{0}{\widehat{D}}$ albuminuric (table II).

In 198020 patients with insulin dependent diabetes के were considered microalbuminuric, 18 of whom could $\overrightarrow{0}$ be re-examined in 1990 . Five patients $(28 \% ; 10 \%$ to $54 \%$ ) had developed macroalbuminuria, six (33\%; $\vec{\omega}$ $13 \%$ to $59 \%$ ) had remained microalbuminuric, and $\frac{\rho}{\circ}$ seven $(39 \% ; 17 \%$ to $64 \%$ ) had urinary albumin ex- 3 cretion which varied between normal and the microalbuminuric range. One macroalbuminuric and one or microalbuminuric patient had died of myocardial $\delta_{\infty}$ infarction (figure). Apart from higher body mass index $\stackrel{-}{-}$ $(\mathrm{p}<0.02)$, the patients who progressed to overt nephropathy could not be clinically distinguished from 의 those who remained microalbuminuric (table III). $\vec{\circ}$ None of the patients who progressed to macro- $\frac{\partial}{\omega}$ albuminuria had developed end stage renal failure.

Twenty two patients had macroalbuminuria in 1980. By 1990 seven had developed end stage renal failure, $\frac{\mathcal{f}}{0}$ 12 remained macroalbuminuric, while three had $\bar{\Phi}_{\mathbb{D}}$ become microalbuminuric. Six patients died of cardiovascular disease during the follow up period (figure).

\section{Discussion}

Our results challenge the view that microalbuminuria is a strong predictor of overt diabetic

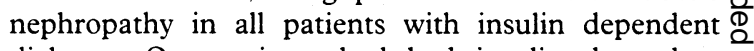
diabetes. Our patients had had insulin dependent $\overrightarrow{\vec{O}}$ diabetes for more than 15 years. The prevalence of $\frac{0}{3}$ overt diabetic nephropathy was $31 \%$ after a mean duration of diabetes of 22.7 years, which is consistent with prevalence data reported from Denmark. ${ }^{\prime 2}$ The mortality in the proteinuric group was increased threefold compared with that in patients with normal albumin excretion rates $(27 \% v 7 \%)$. No increase in $\frac{5}{3}$ mortality was seen in patients with microalbuminuria
$(10 \%)$.

Only five of the 18 patients with microalbuminuria

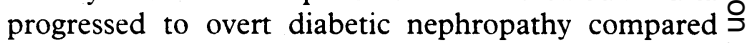
with seven of eight in the study by Viberti $\mathrm{et}^{\mathrm{al}} \mathrm{l}^{3}$ and 12 N out of 14 in the study by Mogensen and Christensen. ${ }^{4}$ D Although our follow up period was slightly shorter than in these two papers, mean duration of diabetes at $N$ initial examination was much longer in our study N (26 years $v 10-14$ years). As $22(31 \%)$ of our patients $\sigma$ had already developed overt nephropathy at initial examination, the microalbuminuric patients may

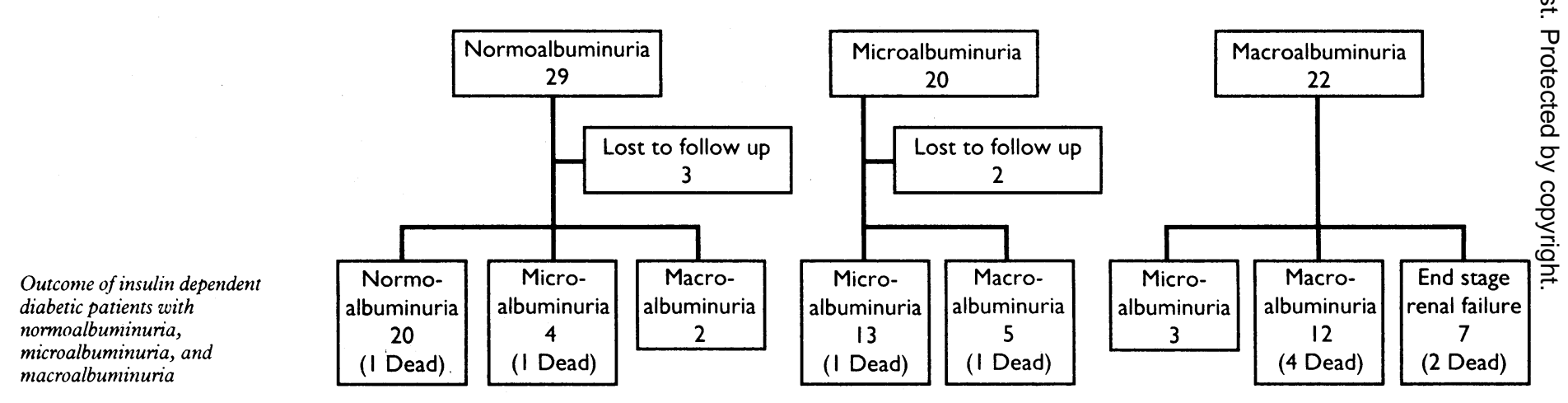


represent a subgroup of patients with a low risk of progression to overt nephropathy. In support of this, the incidence of overt diabetic nephropathy increases steeply 10 years after onset of insulin dependent diabetes mellitus and decreases after 30 years. ${ }^{1}$ In addition, the prevalence of diabetic nephropathy clearly falls after 40 years.

\section{PREDICTIVE FACTORS}

Were there some clinical signs or symptoms to distinguish those patients who developed overt nephropathy from those who did not? In the study by Viberti et al, patients who developed overt nephropathy had a slightly longer duration of diabetes than those who did not. Among our initially normoalbuminuric patients, those who developed microalbuminuria or macroalbuminuria had a shorter duration of diabetes than those who remained normoalbuminuric, suggesting that long duration decreases rather than increases the risk of developing nephropathy in these patients. In addition, patients who developed microalbuminuria or macroalbuminuria had higher glycated haemoglobin concentrations during follow up than those who did not progress, indicating that poor glycaemic control contributed to the development of diabetic nephropathy. The patients who progressed to nephropathy also required a greater daily insulin dose and had lower high density lipoprotein cholesterol concentrations than the patients who remained normoalbuminuric. An increased insulin requirement suggests reduced insulin sensitivity, and low high density lipoprotein cholesterol concentrations have been attributed to insulin resistance." In line with the insulin resistance hypothesis, microalbuminuric patients who progressed to nephropathy had a higher body mass index than those who did not. An association between daily requirement of insulin and incidence of nephropathy has been reported. ${ }^{1}$

\section{SUMMARY}

In conclusion, in patients with insulin dependent diabetes mellitus of long duration microalbuminuria is no longer an important predictor of progression to overt diabetic nephropathy. The data also suggest that signs and symptoms of insulin resistance are common in patients who progress to overt nephropathy. Since the predictive value of microalbuminuria is different in patients with insulin dependent diabetes mellitus of over 15 years' duration, such patients should be excluded from trials aiming at preventing progression from microalbuminuria to overt proteinuria.

We thank Anna-Maija Teppo, for measuring urinary albumin concentrations. This study was supported by grants from the Sigrid Juselius Foundation, the Perklen Foundation, and the Nordisk Insulin Foundation.

1 Andersen AR, Christiansen JS, Andersen JK, Kreiner S, Deckert T. Diabetic nephropathy in twpe I (insulin-dependent) diabetes: an epidemiological study. Diabetologia 1983:25:496-501.

2 Borch-Johnsen K, Andersen PK, Deckert T. The effect of proteinuria on relative mortality in type 1 (insulin-dependent) diabetes mellitus. Diabut clogia 1985:28:590-6.

3 Viberti GC, Hill RD, Jarrett RJ, Argyropoulos A, Mahmud U, Keen $H$ Microalbuminuria as a predictor of clinical nephropathy in insulin-dependen dicroalbuminuna as a predictor of clinica

4 Mogensen CE, Christensen CK. Predicting diabetic nephropathy in insulindependent patients. N Engl F Med 1984;311:89-93.

5 Teppo AM. Immunoturbidimetry of albumin and immunoglobulin $G$ in urine. Clim Chem 1982:28:1359-61

6 Reaven G.M. Role of insulin resistance in human disease. Diabetes 1988;37 $1595-607$.

(Accepted 3 Seplember 1992)
Departments of Public Health, University of Helsinki, Mannerheimintie 96A, SF-00250 Helsinki Arja H Rimpelä, associate professor

Department of Public Health, University of Turku, Lemminkäisenkatu 1, SF-20520 Turku Matti K Rimpelä, acting associate professor

Department of Public Health, University of Tampere, PO Box 607, SF33101 Tampere

Elise A-L Kosunen, clinical lecturer

Correspondence to: $\operatorname{Dr} \mathrm{AH}$ Rimpelä, Department of Public Health, University of Oulu, Aapistiez SF-90220

Oulu, Finland.

\title{
Use of oral contraceptives by adolescents and its consequences in Finland 1981-91
}

\author{
Arja H Rimpelä, Matti K Rimpelä, Elise A-L Kosunen
}

\begin{abstract}
Objectives-To study use of oral contraceptives among Finnish teenagers during 1981-91 and how abortions, childbirths, sexually transmitted diseases, and cardiovascular diseases changed during this period.

Design-Biannual cross sectional surveys with mailed questionnaires from 1981 onwards and analysis of national statistics.

Setting-Finland.

Subjects-A nationwide sample of 14,16 , and 18 year olds. Sample size varied from 1249 to 3887 and response rate from $85 \%$ to $94 \%$.

Main outcome measures-Proportion taking oral contraceptive, fertility and abortion rates, hospital discharge rates, rates of sexually transmitted diseases.

Results-The proportion of teenagers taking oral contraceptives increased steadily. In 1991 the percentages among 14,16 , and 18 year olds were $2 \%$, $18 \%$, and $41 \%$ compared with $0 \cdot 2 \%, 7 \%$ and $22 \%$ in 1981. Most users had a steady partner $(80 \%$ of 16 year olds and $85 \%$ of 18 year olds). By 1989 rates of abortion had fallen from $12 / 1000$ to $9 \cdot 3 / 1000$ in 16 year olds and from $25 / 1000$ to $19 \cdot 2 / 1000$ in 18 year olds; fertility rates had fallen from $4 \cdot 5 / 1000$ to $2 \cdot 3 / 1000$ and from $23 \cdot 5 / 1000$ to $15 \cdot 3 / 1000$ respectively. Rates in 14 year olds fell only slightly. Gonorrhoea infection fell and HIV infection
\end{abstract}

remained rare. Rates of hospital discharge after thromboembolic venous disease rose slightly.

Conclusions-The increased use of oral contraceptives is the most likely explanation for decreasing abortion and fertility rates among teenagers. Increased reliance on the condom because of the threat of AIDS may increase unwanted pregnancies.

\section{Introduction}

The need for contraception among adolescents in developed countries is today undoubtable since sexual experience by late adolescence has become so common as to be normal.' However, fertility and abortion rates in teenagers suggest that the need for contraception is still not satisfied.

The first oral contraceptives introduced in the $1960 \mathrm{~s}$ were not suitable for adolescents because of their adverse effects on the growth and maturation of the menstrual cycle. The new low dose and microdose oral contraceptives overcame these problems and they were recommended for teenagers as well. ${ }^{3.5}$ As oral contraceptives offer a high degree of protection and are well tolerated among adolescents, ${ }^{5}$ increased use could be expected to reduce the rate of unwanted pregnancies.

Although oral contraceptives seem to reduce the risk of pelvic inflammatory disease, ${ }^{\circ}$ they do not protect against sexually transmitted diseases. In the 1980 s the HIV epidemic brought a new element into the discus- 